\title{
Hydrogen isotope exchange in tungsten exposed sequentially to low-energy deuterium and protium ions
}

\author{
V.Kh. Alimov ${ }^{1,2^{*}}$, B. Tyburska-Püschel ${ }^{3}$, M.H.J. 't Hoen ${ }^{4}$, J. Roth ${ }^{3}$, Y. Hatano ${ }^{1}$, K. Isobe ${ }^{2}$, \\ M. Matsuyama ${ }^{1}$, T. Yamanishi ${ }^{2}$ \\ ${ }^{1}$ Hydrogen Isotope Research Center, University of Toyama, Toyama 930-8555, Japan \\ ${ }^{2}$ Tritium Technology Group, Japan Atomic Energy Agency, Tokai, Ibaraki 319-1195, Japan \\ ${ }^{3}$ Max-Planck-Institut für Plasmaphysik, EURATOM Association, D-85748 Garching, Germany \\ ${ }^{4}$ Institute for Plasma Physics Rijnhuizen, EURATOM-FOM, NL-3439 MN Nieuwegein, The Netherlands
}

PACS numbers: 52.40.Hf, 61.72.Qq, 61.80.Jh

\begin{abstract}
Hydrogen isotope exchange in tungsten was investigated at various temperatures both after sequential exposure to low-energy deuterium (D) and protium (H) plasmas and sequential irradiation with low-energy $\mathrm{D}$ and $\mathrm{H}$ ions. The methods used were thermal desorption spectroscopy and the $\mathrm{D}\left({ }^{3} \mathrm{He}, \mathrm{p}\right){ }^{4} \mathrm{He}$ nuclear reaction at ${ }^{3} \mathrm{He}$ energies varied from 0.69 to $4.0 \mathrm{MeV}$ allowing determination of the $\mathrm{D}$ concentration at depths up to $6 \mu \mathrm{m}$. It has been found that a major portion of deuterium initially accumulated in the D-implanted $\mathrm{W}$ is released under subsequent exposure to the $\mathrm{H}$ plasma or irradiated with the $\mathrm{H}$ ions. Depth profiling of $\mathrm{D}$ without and with subsequent $\mathrm{H}$ implantation shows strong replacement close to the surface near room temperatures, but extending to all analyzable depths at elevated temperatures.
\end{abstract}

${ }^{*}$ Corresponding author: e-mail address ㄴahome@mail.ru (V.Kh. Alimov) 


\section{Introduction}

In ITER and DEMO reactors, the tritium inventory is one of the most important safety issue $[1,2]$. Tungsten (W) is one of the candidate plasma-facing materials for the fusion devices due to its low sputtering yield and good thermal properties. As a plasma-facing material, $\mathrm{W}$ will be subjected to intense fluxes of low-energy deuterium and tritium particles. Available data ([3] and references therein, [4]) have shown that the hydrogen isotope retention in $\mathrm{W}$ materials exposed to high flux hydrogen plasmas differs from that low flux ion implantation and can reach relatively high values $\left(\sim 10^{22}\right.$ atoms $\left./ \mathrm{m}^{2}\right)$ at temperatures around $500 \mathrm{~K}$. This tritium inventory in the $\mathrm{W}$ materials would get close to the tritium safety limit in ITER and require removal of the retained tritium. One of possible ways to recover the retained tritium might be hydrogen isotope exchange.

Measurements have been reported around three decades ago for the isotopic replacement of deuterium implanted in several low-Z refractory materials $\left(\mathrm{C}, \mathrm{Si}, \mathrm{B}_{4} \mathrm{C}, \mathrm{TiC}, \mathrm{VB}_{2}, \mathrm{TiB}_{2}\right.$, and $\left.\mathrm{B}\right)$ at room temperature [5, 6, 7, 8,9] and elevated temperatures [10], as well as in 316 stainless steel at $153 \mathrm{~K}$ [11], during subsequent irradiation with protium ions. The observed isotope exchange behavior is in a good agreement with the local mixing model [5] based on the depth dependence of the implanted ions and the experimentally determined hydrogen saturation concentrations. No experimental data on hydrogen isotope exchange in high-Z materials are available.

In this study, hydrogen isotope exchange in tungsten was investigated after sequential exposure to low-energy deuterium (D) and protium (H) plasmas and after sequential irradiation with low-energy $\mathrm{D}$ and $\mathrm{H}$ ions ${ }^{1}$ at various temperatures.

\section{Experimental}

Two types of $\mathrm{W}$ materials were used in this study: ITER-grade W (A.L.M.T. Corp., Japan) and polycrystalline W (Plansee, Austria).

The ITER-grade W with a purity of 99.99 wt.\% is the deformed (rolled, swaged and/or forged) ones followed by appropriate heat-treatments to obtain better mechanical properties, e.g., strength and toughness, after the sintering process. The microstructure of the Japanese ITERgrade $\mathrm{W}$ consists of anisotropically elongated grains along the deformation axis and the grain

\footnotetext{
${ }^{1}$ The term 'low-energy ions' means that the ion energy is below the displacement threshold.
} 
size is around $1 \mu \mathrm{m}$ in section and up to $5 \mu \mathrm{m}$ in length. The elongated grain orientation is defined to be parallel to the heat transfer direction. Square-shaped samples, $10 \times 10 \mathrm{~mm}^{2}$ in size and $2 \mathrm{~mm}$ in thickness, were so prepared by the manufacturer that the irradiated surfaces were perpendicular to deformation axis (i.e., to the heat transfer direction), which corresponds to the ITER specification. The samples were double-side polished and then annealed at $1473 \mathrm{~K}$ for 30 min for stress relief. Prior to D plasma exposure, the samples were cleaned in an acetone ultrasonic bath.

The Plansee polycrystalline $\mathrm{W}$ with a purity of $99.96 \mathrm{wt} . \%$ is a reduced-rolled, powdermetallurgy product with grains of $2-20 \mu \mathrm{m}$ in size. Samples, $12 \times 15 \mathrm{~mm}^{2}$ in size, were cut from a $0.8 \mathrm{~mm}$ thick $\mathrm{W}$ plate and then mechanically polished to mirror-like finish and clean in the acetone ultrasonic bath. Subsequently, the W samples were outgassed at $1200 \mathrm{~K}$ for $2 \mathrm{~h}$ in vacuum with a background pressure of $2 \times 10^{-6} \mathrm{~Pa}$. This temperature is high enough to remove any polishing residue as well as decrease the amount of impurities and intrinsic defects.

The Japanese ITER-grade W samples were exposed the linear plasma generator (LPG) (JAEA Tokai) [12] to a low-energy, high flux D and H plasmas. In the case of D plasma, a plasma beam with species of $\mathrm{D}_{2}^{+}$(over $80 \%$ ) and $\mathrm{D}^{+}$(less than $20 \%$ ) was obtained [12]. It is believed that in the case of protium plasma, the identical percentage of ion species was obtained. A bias voltage of $-80 \mathrm{~V}$ was applied to the $\mathrm{W}$ samples, resulting in an incident energy of $76 \mathrm{eV}$ for $\mathrm{D}_{2}^{+}$or $\mathrm{H}_{2}^{+}(38 \mathrm{eV} / \mathrm{D}(\mathrm{H}))$, taking into account the plasma potential of about $-4 \mathrm{~V}$ as measured by a Langmuir probe. The incident deuterium and protium ion fluxes and fluences were fixed at $10^{22} \mathrm{D}(\mathrm{H}) / \mathrm{m}^{2} \mathrm{~s}$ and $10^{26} \mathrm{D}(\mathrm{H}) / \mathrm{m}^{2}$, respectively. The sample was passively heated by the plasma itself and the exposure temperature was set by the thermal contact between the specimen and the cooled holder. Note that sequential exposure was performed with the same thermal contact; however, the sample temperature under exposure to the $\mathrm{H}$ plasma was slightly higher than that for the D plasma.

The Plansee polycrystalline hot-rolled W samples were irradiated with $200 \mathrm{eV} \mathrm{D}$ and H ions in a vacuum chamber connected to a high-current ion source (HCIS) (IPP Garching) [13] at normal ion incidence. The W samples were irradiated at an ion flux of $4 \times 10^{19} \mathrm{D}(\mathrm{H}) /\left(\mathrm{m}^{2} \mathrm{~s}\right)$ to fluence of $1 \times 10^{24} \mathrm{D}(\mathrm{H}) / \mathrm{m}^{2}$. During irradiation, the W samples were heated up to $320 \mathrm{~K}$ by the ion beam. By electron bombardment from the rear, the irradiation temperature could also be held at higher temperatures. The temperature of irradiation was measured by an infrared pyrometer with an accuracy of $20 \mathrm{~K}$, mainly due to changes of the tungsten emissivity. 
Two sets of experiments were performed: (i) the $\mathrm{W}$ samples were exposed to a deuterium plasma (LPG) and irradiated with D ions (HCIS), and (ii) the W samples were sequentially exposed in-situ to deuterium and protium plasmas (LPG) and irradiated in-situ to D and H ions (HCIS).

Deuterium retention in the $\mathrm{W}$ samples was monitored ex-situ using thermal desorption spectrometry (TDS). An infrared heater was used to heat the samples at a ramp rate of $0.5 \mathrm{~K} / \mathrm{s}$ and the sample temperature was raised to $1300 \mathrm{~K}$. $\mathrm{HD}$, and $\mathrm{D}_{2}$ molecules released during TDS run were monitored by a quadrupole mass-spectrometer (QMS) [4]. Standard $\mathrm{D}_{2}$ leak with an inaccuracy lower than 10\% was employed to calibrate the QMS after each TDS analysis.

The D concentration profiles in the implanted $\mathrm{W}$ specimens were measured by means of the $\mathrm{D}\left({ }^{3} \mathrm{He}, \alpha\right) \mathrm{H}$ reaction, where both the $\alpha$ particles and protons were analyzed. To determine the D concentration at larger depths, an analyzing beam of ${ }^{3} \mathrm{He}$ ions with energies varied from 0.69 to $4.0 \mathrm{MeV}$ was used. The proton yields measured at different ${ }^{3} \mathrm{He}$ ion energies allow measuring the D depth profile at depths of up to $6 \mu \mathrm{m}$ [14].

\section{Results and discussion}

TDS spectra of $\mathrm{HD}$ and $\mathrm{D}_{2}$ molecules for the ITER-grade $\mathrm{W}$ samples exposed to the $\mathrm{D}$ plasma (Fig. 1a) shows that deuterium is thermally released mainly in the form of $\mathrm{D}_{2}$ molecules, although a proportion of $\mathrm{D}$ released in the form of HD molecules increases with decreasing D content and reaches $\sim 30 \%$ after D plasma exposure at $T_{\exp }=725 \mathrm{~K}$. In its turn, after sequential exposure to the $\mathrm{D}$ and $\mathrm{H}$ plasmas, the amount of $\mathrm{D}$ retained in the $\mathrm{W}$ samples deceases significantly as compared to that for the only D plasma exposure. As this takes place, the fraction of deuterium released in the form of HD molecules increases and dominates for implantation at $540 \mathrm{~K}$.

Deuterium depth profiles give detailed information about depths of the deuterium depletion under sequential exposure to the $\mathrm{D}$ and $\mathrm{H}$ plasma. From a comparison of the $\mathrm{D}$ profiles in the ITER-grade $\mathrm{W}$ after D plasma exposure at $335 \mathrm{~K}$ and after subsequent exposure to the D plasma at $355 \mathrm{~K}$ and to the $\mathrm{H}$ plasma at $370 \mathrm{~K}$ (Fig. 2), it is apparent that at relatively low exposure temperatures (below $370 \mathrm{~K}$ ) the deuterium depletion occurs mainly at depths up to $1 \mu \mathrm{m}$. However, at exposure temperatures of about $500 \mathrm{~K}$ and higher, the deuterium depletion takes place across the whole analyzable depth, and the D concentration decreases by approximately 
two orders of magnitude (for example, compare D profile for D plasma exposure only at $490 \mathrm{~K}$ and for sequential exposure to the D plasma at $485 \mathrm{~K}$ and $\mathrm{H}$ plasma at $510 \mathrm{~K}$ (Fig. 2)).

Practically the same effect is found for polycrystalline hot-rolled W subsequently irradiated with $200 \mathrm{eV} \mathrm{D}$ and $\mathrm{H}$ ions (Fig. 3). After sequential irradiation with D and $\mathrm{H}$ ions at $320 \mathrm{~K}$, the deuterium depletion is observed at depths up to $2 \mu \mathrm{m}$. At $T_{\exp }=430-530 \mathrm{~K}$, a release of deuterium under the sequential irradiation occurs across the whole analyzable depth (Fig. 3).

In the ITER-W exposed to the D plasma only, the D total retention as obtained from TDS is about $4 \times 10^{20} \mathrm{D} / \mathrm{m}^{2}$ at $T_{\exp }=335 \mathrm{~K}$ and, as exposure temperature increases, rises to its maximum of about $3 \times 10^{21} \mathrm{D} / \mathrm{m}^{2}$ at $T_{\exp }=490 \mathrm{~K}$ and then decreases down to about $5 \times 10^{19} \mathrm{D} / \mathrm{m}^{2}$ at $T_{\exp }=$ $725 \mathrm{~K}$ (Fig. 4a). The subsequent exposure to the $\mathrm{H}$ plasma leads to a release of $75-90 \%$ of initially retained deuterium (Fig. 4a).

In $\mathrm{W}$ materials irradiated with low-energy $\mathrm{D}$ ions with the use of plasma or ion beams, the depths of $\mathrm{D}$ accumulation (several micrometers) are much larger than the deuterium implantation range (several nanometers), and D concentration at depths of several micrometers reaches relatively high values of $0.01-1$ at. $\%$, depending on irradiation temperature $[4,15]$. The mechanism of plastic deformation due to deuterium supersaturation [16] must be considered for modification of the subsurface structure and formation of trapping sites for deuterium [17, 18]. During D plasma exposure/ion irradiation, the D concentration in the implantation zone greatly exceeds the solubility limit and stresses the matrix lattice until plastic deformation occurs to alleviate the stress [16]. This deformation is assumed to be responsible for the generation of vacancies, microscopic cracks and cavities at depths of several micrometers and the concurrent accumulation of diffusing deuterium. At long-term irradiation the diffusing $\mathrm{D}$ atoms recombine on the cavity surfaces, increasing thus the $\mathrm{D}_{2}$ gas pressure inside these cavities. The stress from supersaturation of $\mathrm{D}$ in the lattice is additionally increased by the high gas pressure inside the cavities.

As illustrated for the example of recrystallized W [15], at exposure/irradiation temperatures above the brittle-to-ductile transition temperature (BDTT) (370-470 K depending on the crystal-lattice orientation $[19,20,21])$ the dislocation mobility is increased and the stress can be relaxed by dislocations moving along lattice planes through the whole crystallite leading to small cavities at the grain boundaries at depths of several tens of micrometers. However, near room temperature, i.e. below BDTT, the stress relaxation results in brittle crack formation inside 
the grains [15]. One would expect that similar phenomena take place both in polycrystalline ITER-grade W and hot-rolled W.

Results reported in this work show that under sequential irradiation of the D pre-implanted $\mathrm{W}$ with low-energy $\mathrm{H}$ ions, a major portion of previously accumulated deuterium is released and replaced by protium. It may be suggested replacement processes occur both in the vacancies and on the surface of the pressurized cavities/cracks resulting in accumulation of $\mathrm{H}_{2}$ and $\mathrm{HD}$ molecules inside the cavities/cracks. Obviously, a stress and high concentration of hydrogen atoms in the solute state maintained by the hydrogen ion irradiation are driving forces for the hydrogen replacement.

Thus, it may be concluded that at long-term irradiation with low-energy hydrogen isotope ions, i.e., at ion fluences above certain fluence required for formation of pressurized cavities/cracks, hydrogen isotopes situated inside these cavities in the molecular form are continuously replaced by isotopes diffusing from the ion implantation zone.

\section{Summary}

Hydrogen isotope exchange has been studied in tungsten after (i) sequential exposure to deuterium and protium plasma beams with ion energy of $38 \mathrm{eV} / \mathrm{D}(\mathrm{H})$ to the same fluences of $10^{26} \mathrm{D}(\mathrm{H}) / \mathrm{m}^{2}$ and (ii) sequential irradiation with $200 \mathrm{eV} \mathrm{D}$ and $\mathrm{H}$ ions to fluences of $10^{24}$ $\mathrm{D}(\mathrm{H}) / \mathrm{m}^{2}$, at various exposure/irradiation temperatures. A major portion of deuterium initially accumulated in $\mathrm{W}$ is released under subsequent exposure to the $\mathrm{H}$ plasma or irradiation with the $\mathrm{H}$ ions. At near room temperature, the deuterium depletion is found at depths up to $1-2 \mu \mathrm{m}$. At exposure/irradiation temperatures above $430 \mathrm{~K}$, the release of deuterium occurs from depths up to $6 \mu \mathrm{m}$ and deeper layers. Thus, under sequential irradiation of the $\mathrm{D}$ pre-implanted $\mathrm{W}$ with low-energy $\mathrm{H}$ ions, a major portion of previously accumulated deuterium is released and replaced by protium, probably due to replacement processes occurred both in vacancies and on the surface of pressurized cavities/cracks. 


\section{Figure capture}

Figure 1. Thermal desorption spectra of $\mathrm{HD}$ and $\mathrm{D}_{2}$ molecules released from ITER-grade W exposed to D plasma only (a) and D and H plasmas sequentially (b) with the same fluences of $10^{26} \mathrm{D}(\mathrm{H}) / \mathrm{m}^{2}$. The exposure temperatures are indicated in the legends. The TDS heating rate was $0.5 \mathrm{~K} / \mathrm{s}$. Note that the release rate scales in panels (a) and (b) are different.

Figure 2. Depth profiles of deuterium retained in ITER-grade W exposed to D plasma only and $\mathrm{D}$ and $\mathrm{H}$ plasmas sequentially with the same fluences of $10^{26} \mathrm{D}(\mathrm{H}) / \mathrm{m}^{2}$. The exposure temperatures are indicated in the legends. Note that the D concentration after sequential exposure to the $\mathrm{D}$ and $\mathrm{H}$ plasmas at $615 \mathrm{~K}(\mathrm{D}) / 670 \mathrm{~K}(\mathrm{H})$ is below the NRA detection limit.

Figure 3. Depth profiles of deuterium retained in polycrystalline hot-rolled W irradiated with 200 $\mathrm{eV}$ D ions only and $200 \mathrm{eV} \mathrm{D}$ and $\mathrm{H}$ ions sequentially with the same fluences of $10^{24} \mathrm{D}(\mathrm{H}) / \mathrm{m}^{2}$. The irradiation temperatures are indicated in the legends. Note that the D concentration after sequential irradiation to $\mathrm{D}$ and $\mathrm{H}$ ions at $530 \mathrm{~K}$ is below the NRA detection limit.

Figure 4. Deuterium retention in ITER-grade $\mathrm{W}$ exposed to D plasma only and to D and H plasmas sequentially with the same fluences of $10^{26} \mathrm{D}(\mathrm{H}) / \mathrm{m}^{2}(\mathrm{a})$, and in polycrystalline hotrolled W irradiated with D ions only and with D and $\mathrm{H}$ ions sequentially to the same fluence of $10^{24} \mathrm{D}(\mathrm{H}) / \mathrm{m}^{2}(\mathrm{~b})$, as a function of the exposure temperature. The total deuterium retention was determined by TDS (solid points), whereas the D retention up to a depth of $6 \mu \mathrm{m}$ was measured by nuclear reaction analysis (open points). 


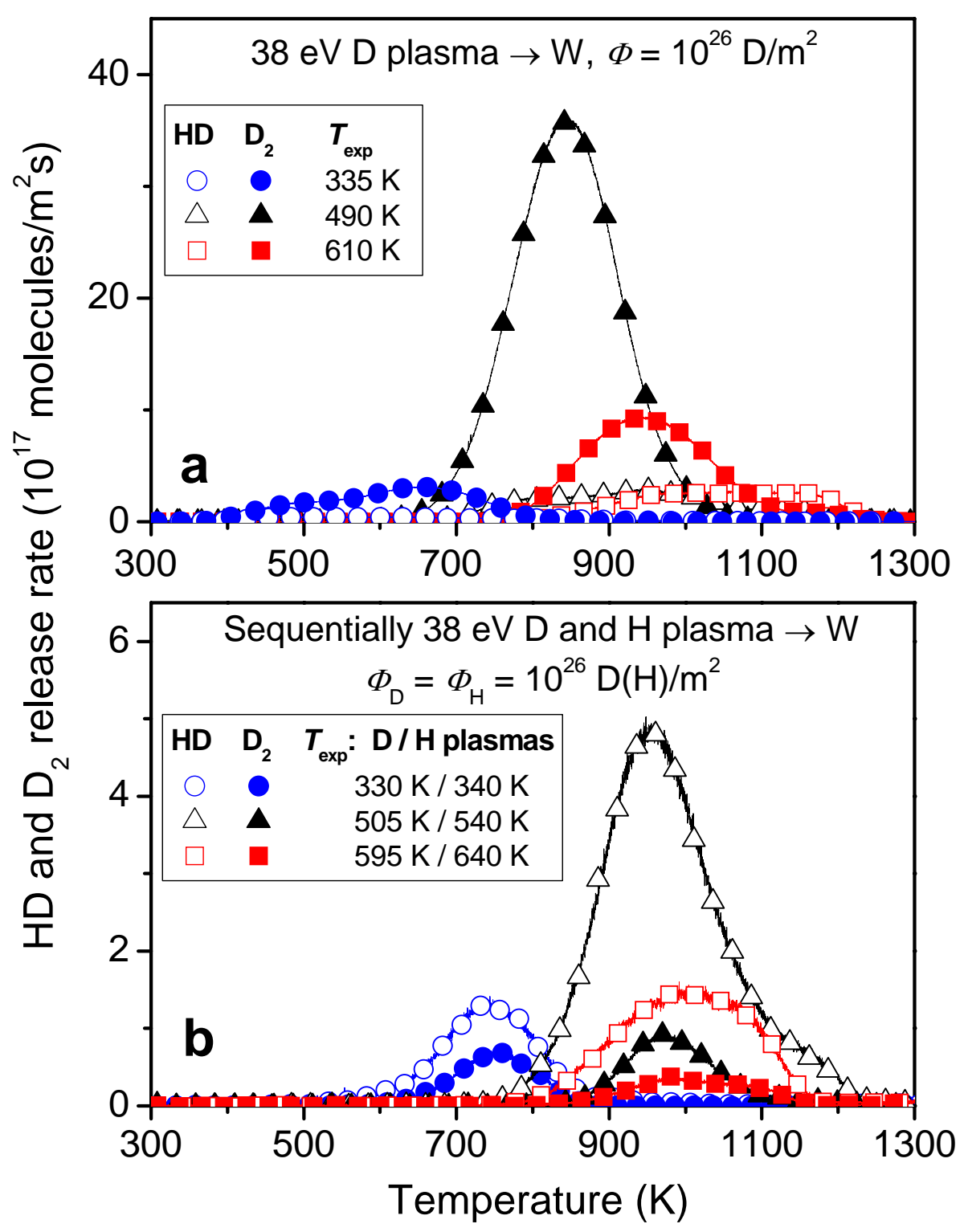

Figure 1. Thermal desorption spectra of $\mathrm{HD}$ and $\mathrm{D}_{2}$ molecules released from ITER-grade W exposed to D plasma only (a) and D and H plasmas sequentially (b) with the same fluences of $10^{26} \mathrm{D}(\mathrm{H}) / \mathrm{m}^{2}$. The exposure temperatures are indicated in the legends. The TDS heating rate was $0.5 \mathrm{~K} / \mathrm{s}$. Note that the release rate scales in panels (a) and (b) are different. 


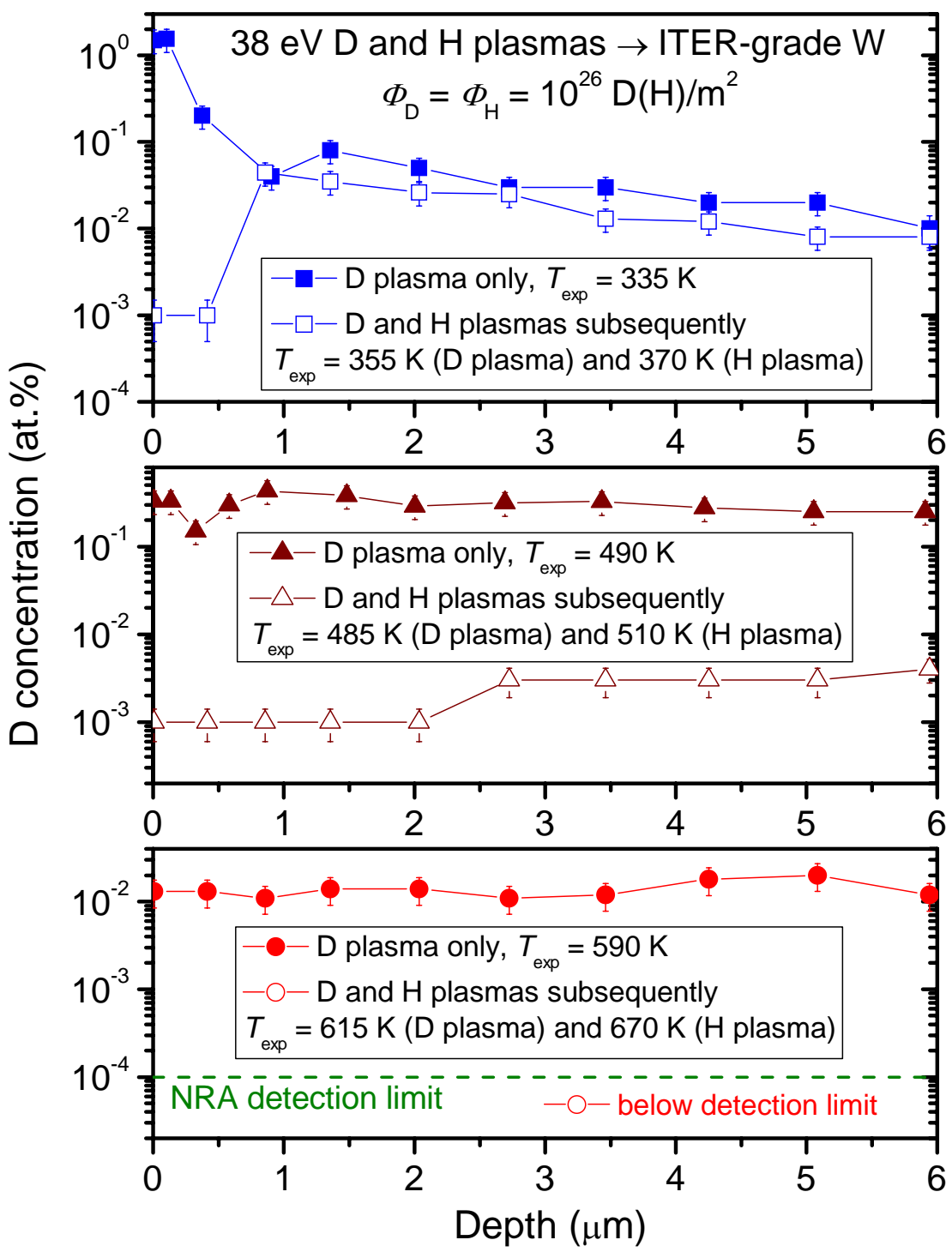

Figure 2. Depth profiles of deuterium retained in ITER-grade W exposed to D plasma only and $\mathrm{D}$ and $\mathrm{H}$ plasmas sequentially with the same fluences of $10^{26} \mathrm{D}(\mathrm{H}) / \mathrm{m}^{2}$. The exposure temperatures are indicated in the legends. Note that the $\mathrm{D}$ concentration after sequential exposure to the $\mathrm{D}$ and $\mathrm{H}$ plasmas at $615 \mathrm{~K}(\mathrm{D}) / 670 \mathrm{~K}(\mathrm{H})$ is below the NRA detection limit. 




Figure 3. Depth profiles of deuterium retained in polycrystalline hot-rolled W irradiated with 200 $\mathrm{eV}$ D ions only and $200 \mathrm{eV} \mathrm{D}$ and $\mathrm{H}$ ions sequentially with the same fluences of $10^{24} \mathrm{D}(\mathrm{H}) / \mathrm{m}^{2}$. The irradiation temperatures are indicated in the legends. Note that the D concentration after sequential irradiation to $\mathrm{D}$ and $\mathrm{H}$ ions at $530 \mathrm{~K}$ is below the NRA detection limit. 


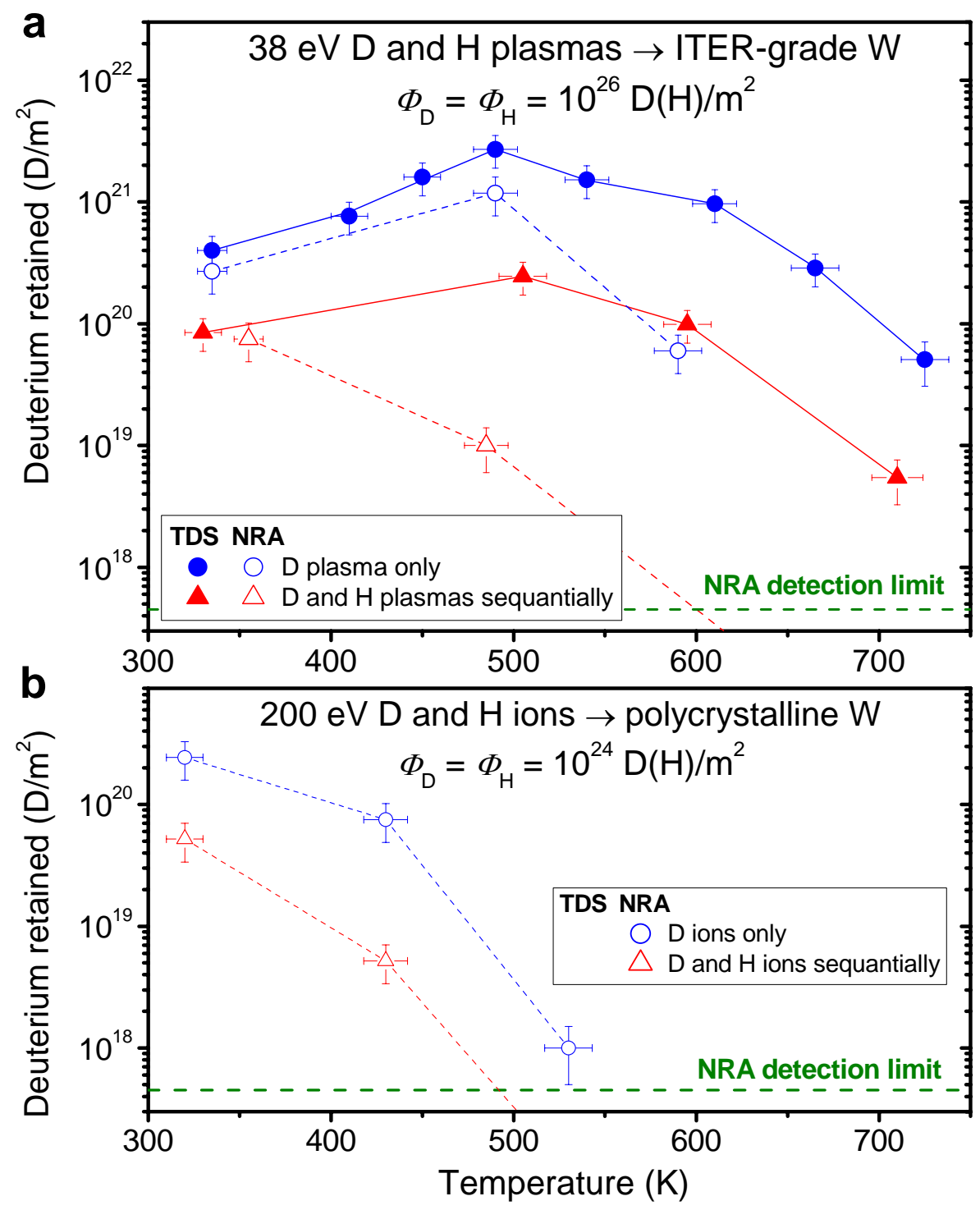

Figure 4. Deuterium retention in ITER-grade $\mathrm{W}$ exposed to D plasma only and to D and H plasmas sequentially with the same fluences of $10^{26} \mathrm{D}(\mathrm{H}) / \mathrm{m}^{2}(\mathrm{a})$, and in polycrystalline hotrolled $\mathrm{W}$ irradiated with $\mathrm{D}$ ions only and with $\mathrm{D}$ and $\mathrm{H}$ ions sequentially to the same fluence of $10^{24} \mathrm{D}(\mathrm{H}) / \mathrm{m}^{2}(\mathrm{~b})$, as a function of the exposure temperature. The total deuterium retention was determined by TDS (solid points), whereas the D retention up to a depth of $6 \mu \mathrm{m}$ was measured by nuclear reaction analysis (open points). 


\section{References}

[ $\left.{ }^{1}\right]$ Federici G et al (2001) Nucl. Fusion 411967

$\left[{ }^{2}\right]$ Tobita K et al (2006) Fusion Eng. Des. 811151

$\left[{ }^{3}\right]$ Skinner C H et al (20080 Fusion Sci. Technol. 54891

$\left[{ }^{4}\right]$ Alimov V Kh et al (2011) J. Nucl. Mater. doi:10.1016/j.jnuclmat.2011.01.088

$\left[{ }^{5}\right]$ Doyle B L et al (1980) J. Nucl. Mater. 93 \& 94551

$\left[{ }^{6}\right]$ Underwood M C, Erents S K, Hotston E S (1980) J. Nucl. Mater. 93 \& 94575

$\left[{ }^{7}\right]$ Roth J et al (1980) J. Nucl. Mater. 93 \& 94601

$\left[{ }^{8}\right]$ Wampler W R, Magee C W (1981) J. Nucl. Mater. 103 \& 104509

$\left[{ }^{9}\right]$ Boutard D, Möller W, Scherzer B M U (1990) Radiat. Effects 114281

$\left[{ }^{10}\right]$ Doyle B L, Wampler W R, Brice D K (1981) J. Nucl. Mater. 103 \& 104513

$\left[{ }^{11}\right]$ Blewer R S et al (1978) J. Nucl. Mater. 76 \& 77305.

$\left[{ }^{12}\right]$ Luo G-N et al (2004) Rev. Sci. Instrum. 754374

$\left[{ }^{13}\right]$ Eckstein W et al (1993) Sputtering Data (Tech. Rep. IPP 9/82 Garching)

$\left[{ }^{14}\right]$ Alimov V Kh, Mayer M, Roth J (2005) Nucl. Instr. and Meth. B 234169

$\left[{ }^{15}\right]$ Lindig S et al (2009) Phys. Scr. T 138014040

$\left[{ }^{16}\right]$ Condon J B and Schober T (1993) J. Nucl. Mater. 2071

$\left[{ }^{17}\right]$ A.A. Haasz, M. Poon, J. Davis (1999) J. Nucl. Mater. 266-269 520

$\left[{ }^{18}[\right.$ Alimov V Kh, Roth J, Mayer M (2005) J. Nucl. Mater. 337-339 619

$\left[{ }^{19}\right]$ Gumbsch P et al (1998) Science 2821293

$\left[{ }^{20}\right]$ Gumbsch P (2003) J. Nucl. Mater. 323304

$\left[{ }^{21}\right]$ Giannattasio A et al (2007) Phys. Scr. T 12887 